\title{
Terapia analítico-comportamental para mulheres com ansiedade e depressão: comportamentos e procedimentos na interação terapêuticao
}

\author{
Analytic-behavioral therapy for women with anxiety and depression: behaviors \\ and procedures in the therapeutic interaction \\ Terapia analítica-conductual para mujeres con ansiedad y depresión:
comportamientos y procedimientos en la interacción terapêutica \\ Giovanna Eleutério Levatti ${ }^{1}$, Alexandre Aguiar Victuri ${ }^{2}$, Vagner Angelo Garcia ${ }^{3}$, Alessandra Turini Bolsoni-Silva ${ }^{4}$
}

[1][2][3][4] Universidade Estadual Paulista Júlio de Mesquita Filho- Unesp campus Bauru I Título abreviado: Terapia analítico-comportamental para ansiedade e depressão I Endereço para correspondência: Laboratório de Aprendizagem, Desenvolvimento e Saúde (LADS), Edifício CASCA 4, Universidade Estadual Paulista Júlio de Mesquita Filho, Av. Eng ${ }^{\circ}$ Luiz Edmundo Carrijo Coube, 14-01 - Vargem Limpa - Bauru-SP - CEP: 17033-360 I Email: bolsoni@fc.unesp.br I DOI: 10.18761/ PAC.2018.N2.02 
Abstract: Anxiety and depression disorders present high prevalence in women. The present article describes behaviors and behavioral analytical intervention procedures in single case delineation. The participants were two women with clinical symptoms of anxiety and depression, who responded to social skills and mental health instruments in four moments (pre-test, intermediate, post-test and follow-up). After the intervention and in the follow-up, the symptoms of anxiety and depression became non-clinical, and there was acquisition of social skills during the process. Regarding the therapeutic interaction, the highlights were the behaviors facilitation, report request, reflection request and approval by the therapists, and the behaviors report, relation establishment, improvement and self-knowledge/self-control by the clients. The most frequent intervention procedures were functional analysis and differential reinforcement. The results pointed out that the occurrence of some behaviors, themes and procedures did not vary between the therapist-client dyads, which indicates a certain stability of the behavioral approach for since it can indicate the constancy of the management used for the participants of this study. The study allowed us to describe behavior and intervention procedures with evidence of improvement in the problems presented previously.

Keywords: Analytical-Behavioral Therapy, Depression, Anxiety, Therapeutic Interaction, Women

Resumen: Los trastornos de ansiedad y depresión presentan alta prevalencia en mujeres. El presente artículo describe comportamientos y procedimientos de intervención analítica comportamentales, en el diseño de un solo caso. Participaram dos mujeres que sufren de ansiedad y depresión, han respondido a instrumentos de habilidades sociales y de salud mental en cuatro momentos (pre-test, intermedio, post-test y seguimiento). Después de la intervención y en el seguimiento los síntomas de ansiedad y depresión se tornaron no clínicos y hubo adquisición de habilidades sociales. En cuanto a la interacción terapéutica hubo el destaque de los comportamientos de facilitación, de solicitud de relato, de solicitud de reflexión y de aprobación en cuanto al repertorio de los terapeutas y de comportamientos de relato, de establecimiento de relaciones, de mejora y de autoconocimiento/autocontrol en lo que se refiere al repertorio de los clientes. Los procedimientos de intervención con mayor ocurrencia fueron el análisis funcional y el refuerzo diferencial. Los resultados apuntaron que la ocurrencia de algunos comportamientos, temas y procedimientos no varía entre las díadas terapeuta-cliente, lo que indica cierta estabilidad del abordaje conductual, dado que puede indicar la constancia de los manejos utilizados para las participantes de este estudio. El estudio permitió describir comportamientos y procedimientos de intervención con evidencias de mejora en los cuadros presentados anteriormente a la misma.

Palabras-clave: Terapia Analítica-Comportamental, Depresión, Ansiedad, Interacción Terapéutica, Mujeres

Nota: Este artigo é derivado de uma pesquisa de mestrado da primeira autora, financiada pela FAPESP (Fundação de Amparo à Pesquisa do Estado de São Paulo) Processo 2015/ 10230-9, e de uma pesquisa de iniciação científica, do segundo autor, financiada pelo CNPq (Conselho Nacional do Desenvolvimento Científico e Tecnológico); ambas sob orientação da quarta autora. 
Atualmente, casos de ansiedade e depressão têm apresentado aumento na população, tanto em âmbito nacional, quanto internacional. Relatório publicado pela Organização Mundial da Saúde (OMS, 2017), abrangendo transtornos depressivos e transtornos ansiosos presentes com alta frequência na população, informa que houve aumento no número de pessoas com diagnóstico de tais transtornos. No caso de pessoas com diagnóstico de depressão, houve aumento de $18,4 \%$, entre 2005 e 2015 . Já em relação a pessoas com diagnóstico de ansiedade, em 2005 eram 264 milhões, enquanto 2015 refletiu um aumento de $14,9 \%$ considerando o período dos dez anos anteriores. (Organização Mundial da Saúde [OMS], 2017).

O Transtorno Depressivo Maior (TDM) é a condição clássica dos denominados transtornos depressivos de acordo com o Manual Diagnóstico e Estatístico de Transtornos Mentais-5 (DSM-5, APA, 2013), compreendendo sintomas de humor deprimido, alteração no apetite, e interferência na disposição para a realização das atividades diárias, entre outras. Mulheres são mais acometidas por depressão que homens, sendo a incidência de aproximadamente $5,1 \%$ entre mulheres e $3,6 \%$ entre homens (OMS, 2017). Do ponto de vista da Análise do Comportamento, sintomas de depressão estão relacionados ao pouco contato com estímulos reforçadores, de forma que o indivíduo depressivo emite comportamentos funcionais com baixa frequência, por consequência, não atinge o acesso aos reforçadores. (Abreu \& Abreu, 2017). A ativação comportamental, intervenção já consolidada como baseada em evidência para casos de pessoas com diagnóstico de depressão, consiste em identificar atividades com valor reforçador e traçar metas a curto e a longo prazo envolvendo a interação da pessoa em tais atividades, para se comportar de forma a ter acesso a esses reforçadores (Sturmey, 2009).

Em relação aos transtornos de ansiedade é imprescindível observar que embora sentir medo e ansiedade possa ter função adaptativa, no caso da patologia, há a diferenciação pelo excesso (APA, 2013). Os critérios diagnósticos do DSM5 (APA, 2013) para o Transtorno de Ansiedade Generalizada incluem ansiedade e preocupação excessivas, inclusive com dificuldade em controlar a preocupação. Segundo a OMS (2017), em 2015, a proporção de pessoas com ansiedade foi de 4,6\% entre as mulheres e $2,6 \%$ entre os homens, em níveis globais. Os comportamentos ansiosos apresentam a função, geralmente, de se esquivar ou fugir de situações com valor aversivo, de forma que evita o "aversivo", e produz reforçadores negativos (Zamignani \& Banaco, 2005).

Em relação ao Brasil, a situação segue a tendência mundial, sendo os transtornos mentais mais prevalentes na rede de atenção primária (Gonçalves et al., 2014). Quando aparecem em comorbidade, isto é, a presença de dois ou mais transtornos mentais simultaneamente (Araújo, Ronzani \& Lourenço, 2010), há pior prognóstico para o tratamento, sendo quadros de maior duração e com mais comprometimentos, dada a severidade dos sintomas e prejuízo funcional (Araújo et al., 2010; Johanson, Carlbring, Heedman, Paxling, \& Andersson, 2013; Newby et. al., 2013; Starr, Hammen, Connolly, \& Brennan, 2014).

$\mathrm{Na}$ literatura existem estudos sobre tratamento de quadros de comorbidade de ansiedade e depressão. Desses estudos, destaca-se um conduzido com mulheres com infertilidade (Faramarzi et al., 2008), outros em abordagem TCC (Van Beek et al., 2013; Newby et al, 2013) e resultados da aplicação da terapia denominada Mindfulness, CompassionMindfulness Therapy (Herman, Siu Man, Chan, Lam, \& Lau, 2013). Os resultados apontaram que houveram reduções significativas na depressão e ansiedade. Contudo, essas pesquisas apresentavam medidas de resultado, apenas, e não avaliavam a interação entre terapeuta e cliente nesse processo, evidenciando uma lacuna na literatura, que se acentua em relação a tais estudos na abordagem Analítico-Comportamental, foco deste trabalho.

\section{Terapia Analítico-comportamental}

Destaca-se que a despeito de haver poucas evidências sobre a Terapia Analítico-Comportamental de maneira geral nos estudos brasileiros (Leonardi \& Meyer, 2015), há evidências que a Ativação Comportamental é eficaz no tratamento de depressão (Abreu \& Abreu, 2017) e que a técnica de exposição e prevenção de resposta é a recomendada no tratamento de transtorno de ansiedade (Zamignani \& Banaco, 2005). 
Psicólogos que norteiam sua prática clínica de acordo com a Análise do Comportamento praticam a Terapia Analítico-Comportamental (TAC). Segundo Meyer et al. (2010), a TAC, pode ser definida da como “... uma forma de prestação de serviços que utiliza o arcabouço teórico da análise do comportamento e o conhecimento de pesquisas básicas e aplicadas para a solução de problemas humanos" (p. 172). Os psicólogos analistas do comportamento, além das diversas técnicas que têm conhecimento, devem se atentar também para a relação construída com o cliente (de-Farias, 2010) e ter por principal instrumento de avaliação e intervenção a análise funcional (Abreu \& Abreu, 2017).

Em relação às pesquisas em psicologia clínica no âmbito analítico- comportamental, é importante que o (a) pesquisador (a) se atente para a análise das relações funcionais, ou a singularidade do fenômeno a ser estudado, campo do estudo do sujeito único (Matos, 1990). Dessa forma, os estudos de caso único $(\mathrm{n}=1)$ podem ser considerados característicos da análise do comportamento, experimental e aplicada (Shaughnessy, Zechmeister \& Zechmeister, 2012). Matos (1990) destacou que no trabalho norteado pela Análise do Comportamento não se pode afirmar que tratamos como iguais os participantes de uma pesquisa, haja vista que são diferentes entre si. Para Koerner (2018) coletar dados regularmente, portanto monitorar o progresso de cada um dos clientes, em cada sessão, é muito importante para prevenir fracasso e abandono. Destacando-se, assim, que pesquisa em clínica precisa fazer uso de medidas de resultado e de processo e garantir a singularidade de cada participante.

Ao trabalhar com sujeito único $(\mathrm{N}=1)$ pode-se respeitar o caráter singular e processual do comportamento (Andery, 2010), conduzindo medidas antes, durante e depois da intervenção, ou com a introdução da variável independente, de maneira que possibilite a análise do processo ocorrido com o comportamento do participante ao longo do estudo (Matos, 1990; Andery, 2010). Nesse delineamento, os dados são tratados considerando o participante de forma individual, de forma que o controle utilizado para o participante da pesquisa é ele mesmo (Matos, 1990; Andery, 2010; Shaughnessy et. al, 2012).

A partir de busca realizada no portal de periódicos científicos da CAPES (busca avançada), entre os anos de 2005 a 2015 quanto à estudos de intervenção com pessoas que apresentavam quadros clínicos de ansiedade, depressão e em comorbidade, verificou-se que eram poucas as pesquisas que avaliaram medidas de resultados e processos simultaneamente, não sendo encontrados estudos conduzidos com base na TAC. De maneira geral, garantindo particularidades, as intervenções mostraram-se efetivas, ainda que parte das pessoas não tenham superado os sintomas clínicos (Chagas, Guilherme \& Moriyama, 2013; Dougher \& Hackbert, 2003; Faramarzi et al., 2008; Van Beek et al., 2013; Newby et al., 2013; Herman et al., 2013). Diante desses achados, torna-se importante e relevante o estudo de efeitos de intervenções analítico-comportamentais com essa população de interesse, para verificar a aplicabilidade, eficácia e eficiência da mesma, possibilitando descrever a interação entre cliente e terapeuta.

\section{Interação Terapêutica}

A interação entre terapeuta e cliente é um tópico fundamental a ser trabalhado ao dissertar sobre psicologia clínica (Shinohara, 2000). Segundo Alves e Isidro-Marinho (2010), a interação terapêutica se apresenta como modo de auxílio, uma vez que com o conhecimento teórico irá auxiliar o cliente a enfrentar as dificuldades que caracterizam as queixas clínicas. Dessa forma, ao tratar do tema processo psicoterapêutico, é importante citar a análise da interação terapêutica, caracterizada pelos comportamentos de cliente e terapeuta em interação (Zamignani \& Meyer, 2007).

Interação terapêutica é definida por Zamignani e Meyer (2007) como "um processo de modelagem mútua, em um fluxo contínuo de interações." (p. 252). Ou seja, pode-se afirmar que a interação terapêutica trata dos comportamentos do terapeuta $\mathrm{e}$ cliente em ambiente de sessão, e do alcance que um exerce sobre o outro, ao longo do processo terapêutico (Braga \& Vandenberghe, 2006).

Ruiz-Sancho, Frojan-Parga e Calero-Elvira (2013) realizaram análise de 19 casos clínicos, atendidos por terapeutas com formação em análise do comportamento, sendo a hipótese inicial de que o comportamento do terapeuta sofria influência do 
comportamento do cliente. Os autores concluíram que o terapeuta emite o comportamento de acordo com as falas do cliente, dependendo se a fala vai em direção ou contra os objetivos propostos. Semelhante estudo foi desenvolvido por Silveira e Kerbauy (2000) que descreveram um estudo de caso em análise do comportamento com queixas relacionadas a problemas com alimentação. Analisando as verbalizações, as autoras observaram que inicialmente o comportamento da terapeuta parece ter ficado sob controle da descrição da queixa, o que pareceu ter se modificado ao longo do processo, evidenciando o aspecto flexível do processo terapêutico.

Em relação a pesquisas sobre interação terapêutica com clientes que apresentam quadros de ansiedade, pode-se encontrar o estudo de Zamignani e Andery (2005). Por meio do estudo de categorização das gravações de sessões, os autores observaram que houve diferenças entre as categorias de respostas mais emitidas por terapeutas comportamentais distintos, pois, enquanto um emitiu com maior frequência a categoria "Aprovação", o outro terapeuta emitiu com maior frequência as categorias "Aconselhamento" e "Explicação". Dessa forma, um estudo que envolva mais de um terapeuta diante de pacientes de mesmo diagnóstico, com aplicação do mesmo procedimento, permite maior compreensão do processo e análise da interação terapeuta-cliente, podendo descrever regularidades e particularidades de acordo com cada caso. Como afirma Skinner (1953, pag. 15) "Ciência é a busca de ordem, de uniformidade, de relações entre os eventos na natureza sujeitas a leis.", ainda que cada caso seja único em sua história de aprendizagem. Então, seguindo recomendação de Skinner (1953), é interessante identificar regularidades visto que pode auxiliar o cientista comportamental e o clínico formular regras sobre quais estratégias tem apresentando evidência de melhora no tratamento de determinado quadro.

Estudo realizado no âmbito da interação terapêutica, sob a perspectiva comportamental, foi desenvolvido por Zamignani (2007). Por meio de revisão de literatura, elaborou um sistema de categorias de análise da interação terapêutica, denominado Sistema Multidimensional de Categorização de Comportamentos da Interação Terapêutica
(SiMCCIT). O sistema de categorias foi desenvolvido em três eixos: Comportamento Verbal - Eixo I; Temas - Eixo II e Respostas Motoras - Eixo III. Diversos estudos deram segmento ao trabalho de Zamignani (2007) aplicando seu sistema de categorias (Del Prette \& Meyer, 2014; Fogaça, Meyer \& Bolsoni - Silva, 2014; Melo, Aureliano \& Zamignani, 2014; Donadone \& Meyer, 2014; Oshiro \& Meyer, 2014).

Um exemplo de estudo descritivo de interação terapêutica com clientes com diagnóstico de ansiedade é Garcia et al. (2017) que envolveu um terapeuta em atendimento individual a dois clientes, por meio do SiMCCIT (Zamignani, 2007). Foi observado que as categorias do terapeuta que apareceram com maior frequência foram gestos de concordância e facilitação. Para ambos os clientes a categoria relato apresentou alta frequência. Para as categorias de temas da sessão ambos os clientes apresentaram como tema de maior frequência durante o início e desenvolvimento do processo terapêutico Relações Interpessoais, de forma que ao Encerramento do processo terapêutico, a categoria manteve-se para $\mathrm{P} 1$, enquanto para $\mathrm{P} 2$ o tema Relações com cônjuge/parceiro se destacou ao final do processo.

A partir do exposto, pode-se levantar a questão sobre a efetividade da TAC para os casos de comorbidade em ansiedade e depressão, principalmente no caso de mulheres que apresentam maior frequência de diagnóstico. Nesse sentido, pode-se indagar quais categorias de comportamento do terapeuta e cliente ocorrem com maior frequência e duração em casos nos quais o atendimento com TAC foi bem-sucedido, além da descrição dos procedimentos de intervenção utilizados, em termos de frequência e duração. Dessa forma, torna-se relevante um estudo que descreva medidas de resultado e de interação terapêutica concomitantemente, para quadros de ansiedade e depressão em comorbidade, sendo o foco do presente estudo.

\section{Método}

O estudo consiste em delineamento de sujeito único. Todas as participantes desta pesquisa declararam estar de acordo mediante a assinatura do 
Termo de Consentimento Livre e Esclarecido permitindo o uso dos dados das intervenções para fins de pesquisa. O trabalho foi aprovado pelo Comitê de Ética (1.185.009).

\section{Participantes}

Participaram deste estudo duas mulheres com sintomas de ansiedade e depressão, usuárias de uma clínica-escola de uma universidade pública no centro-oeste paulistano. As clientes são denominadas de P1 e P2; sendo que P1 fazia uso de medicação há 14 anos, enquanto P2 fazia uso de medicação há 10 anos, mantendo o quadro sintomático de ansiedade e depressão quando iniciaram a terapia. Também participaram da pesquisa duas graduandas do último ano do curso de Psicologia que cursavam o estágio curricular em Psicologia Clínica - Abordagem Comportamental.

A idade das participantes variou entre 41 e 47 anos e elas apresentavam queixas relacionadas aos sintomas dos transtornos de ansiedade e de depressão, que foram confirmados com a aplicação do BAI (Beck Anxiety Inventory - Inventário de ansiedade de Beck) e BDI (Beck Depression Inventory - Inventário de Depressão de Beck) (Cunha, 2001). Ambas tinham filhos e as idades dos filhos eram 24 e 26 anos para P1 e 16 anos para P2. Além disso, as duas eram casadas e exerciam trabalho remunerado fora de casa ( $\mathrm{P} 1$, manicure e $\mathrm{P} 2$, técnica de farmácia), local onde também tinham funções as quais demandavam interação social. As clientes faziam uso de medicação da classe dos antidepressivos e ansiolíticos (Sertralina para P1 e Sertralina e Amitriptilina para P2). Além disso, há semelhança na história de vida das duas clientes, por exemplo, relataram dificuldades de relacionamento com o pai, cuja interação foi permeada por práticas educativas negativas durante a infância e adolescência.

\section{Procedimento de intervenção}

As participantes, que haviam se inscrito para atendimento em uma clínica-escola e passado por triagem, foram chamadas para a participação na pesquisa por atingir aos critérios de inclusão de apresentar sintomas que abrangiam tanto quadro de ansiedade quanto de depressão e não estarem passando por atendimento psicológico naquele momento. Todas passaram por intervenção TAC, sendo o atendimento individual, com sessões semanais ao longo de nove meses de um ano letivo. As participantes eram recebidas na recepção pela estagiária responsável pela intervenção, a duração de cada sessão foi em torno de 50 minutos. P1 e P2 totalizaram 30 sessões de atendimento cada em um ano letivo. Nas intervenções foram utilizados procedimentos diversos (tais como análise funcional, modelagem por aproximação sucessivas, reforçamento diferencial, tarefas de casa, modelação e role playing) de forma a ensinar o autoconhecimento, o responder a regras que descrevessem contingências, o ensino de comportamentos que aumentassem a ativação comportamental, incluindo o treino de habilidades sociais e de outros repertórios que produzissem reforçadores no ambiente de trabalho, familiar e social (Abreu \& Abreu, 2017) e de exposição e prevenção de respostas (Zamignani \& Banaco, 2005).

\section{Instrumentos para mensuração de resultados}

As participantes da pesquisa responderam aos seguintes instrumentos:

Roteiro de Entrevista Clínica. É um instrumento qualitativo composto por perguntas abertas, desenvolvido para identificar queixas e estabelecer objetivos, auxiliando na composição da formulação de caso de cada participante. Contém perguntas como o que motivou a procura pelo atendimento, quais queixas estão presentes, buscando identificar antecedentes e consequentes, histórico da queixa e classes de respostas. A utilização deste roteiro fundamenta, então, a elaboração de análises funcionais e também investiga repertórios de entrada que são recursos.

Inventário de Ansiedade de Beck. Desenvolvido por Beck e Steer (1990) e validado para a população brasileira por Cunha (2001) consiste em uma escala respondida por meio do auto relato, composta por descrições de sintomas de ansiedade, a partir do DSM, sendo que para cada item há quatro alternativas que subentendem graus crescentes de ansiedade. O respondente deve assinalar a alternativa que mais representa o nível de desconforto com cada sintoma. Para obter o escore total, somam-se 
as pontuações de todos os itens, resultando na classificação de nível mínimo, leve, moderado ou grave para transtorno de ansiedade. Esse teste é utilizado para diagnosticar transtornos de ansiedade, com foco no Transtorno de Ansiedade Generalizada.

Inventário de Depressão de Beck. Desenvolvido por Beck e Steer (1993) e validado para a população brasileira por Cunha (2011), consiste em uma escala respondida por meio do auto relato, composta por afirmações descritivas de sintomas de depressão, com base no DSM, sendo que para cada item há quatro alternativas que subentendem graus crescentes de depressão, cujos escores variam de zero a três. O respondente deve assinalar todas as alternativas que julgar coerentes para si. Para obter o escore total é necessário somar os escores individuais dos itens, considerando somente as pontuações dos itens de maior valor em cada item, resultando na classificação de nível mínimo, leve, moderado ou grave para transtorno depressivo. Esse teste é utilizado para diagnosticar transtorno depressivo, principalmente o Transtorno Depressivo Maior.

Patient Health Questionnarie. Desenvolvido por Spitzeret al. (1999) e por Kroenke, Spitzer e Williams (2001) é validado para participantes do sexo feminino por Osório, Mendes, Crippa e Loureiro (2009). Consiste em um instrumento de auto relato baseado diretamente nos critérios diagnósticos para Desordem de Depressão Maior do DSM-IV. A partir de perguntas sobre a frequência da ocorrência de sintomas de ansiedade e depressão, com alternativas que que subentendem graus crescentes de depressão, possibilita tanto o rastreamento de sinais e sintomas do Transtorno Depressivo Maior (nome atual) como a classificação de níveis de gravidade, leve, moderada e grave, sendo que quanto maior o escore, mais indicadores de problemas.

\section{Inventário de Habilidades Sociais (IHS- Del} Prette). Desenvolvido por Del Prette e Del Prette (2001), consiste em um instrumento de auto relato composto por asserções descritivas de situações e ações, para as quais o respondente deve assinalar uma probabilidade de ocorrência (variando de nunca a sempre, de acordo com as legendas, de A a
E), tomando como base o seu repertório. A partir de um crivo de correção, são atribuídos valores a cada uma das respostas. $\mathrm{Na}$ folha de correção, esses valores são associados a habilidades sociais específicas (tais como manter conversação e recusar pedidos abusivos) e podem ser comparados com os da média da população. A cada valor (de 0 a 4), pode ser atribuído um escore em cada questão. Os escores podem ser somados para obter um escore total ou escores fatoriais que representam dimensões das habilidades sociais, tais como enfrentamento e autoafirmação com risco e autocontrole da agressividade. Em resumo, é um instrumento que mensura e avalia habilidades sociais presentes no repertório do respondente. As normas de referência não foram utilizadas porque são apropriadas apenas para universitários.

\section{Instrumentos para mensuração de processos}

Os seguintes instrumentos foram utilizados para a categorização dos dados observados nas sessões:

Protocolo de Observação Comportamento do Terapeuta e do Cliente. A análise da interação terapêutica se deu por meio do recurso auditivo. Dessa forma, foram utilizados arquivos de áudio com a gravação das intervenções. Para o estudo das categorias foi utilizado o Protocolo de Observação (Zamignani, 2007), com as definições das categorias comportamentais relacionadas ao Eixo I: comportamento verbal do Terapeuta e do Cliente, além de categorias inclusas pela pesquisadora baseada no Treino de Habilidades Sociais desenvolvido por Bolsoni-Silva (2009). Também foi utilizado o software The Observer XT 7.0 para a categorização das sessões. As categorias de comportamentos são classificadas de acordo com a função que exercem na relação terapêutica. Para as terapeutas, variam desde solicitação de relato até aprovação. Para as clientes, variam de relato até estabelecer relações.

Protocolo de Observação Temas. Foram analisadas também as categorias referentes ao tema de sessão, cujo Protocolo de Observação (Zamignani, 2007; Bolsoni Silva, 2009), com as categorias de tema inclusas no Eixo II, e inclusos os temas incluídos no Treino de Habilidades Sociais desenvolvido por 
Bolsoni Silva (2009). De modo geral, as categorias de temas se referem ao tipo de comportamento abordado (fazer críticas, comunicação etc.) e/ou ao contexto em que ocorrem (filhos, cônjuge, trabalho).

Protocolo de Observação Procedimentos de Intervenção. Foi elaborado a partir de Del Prette e Almeida (2012) e consta as seguintes categorias de análise: Análise Funcional, Role-Playing, Modelo, Reforçamento Diferencial de Comportamento Alvo, Instrução, Entrevistas e Instrumentos Padronizados e Auto Revelação.

\section{Procedimento de coleta de dados}

Os dados foram coletados em uma clínica escola de uma universidade pública do centro-oeste paulista. Foram coletadas as medidas comportamentais Préteste (início do tratamento), medida intermediária (após quatro meses do início do tratamento) e Pósteste (nove meses após o início do tratamento). A medida de Seguimento foi coletada dois meses após o Pós-teste. As duas terapeutas estagiárias participaram de supervisões presenciais semanais com a mesma professora do Departamento de Psicologia, além de redigirem relatórios semanais que eram corrigidos pela mesma supervisora, de modo que a integridade e a regularidade do tratamento fossem mantidas.

\section{Análise de concordância}

A análise dos áudios das sessões foi realizada pela pesquisadora e por uma observadora. Em primeiro momento, a pesquisadora elaborou o Protocolo de Observação para Categorias, seguindo uma discussão com a observadora, estudante de mestrado e Terapeuta Analítico-Comportamental, que sugeriu algumas modificações. Em um primeiro momento ambas as observadoras estudaram os protocolos e, na sequência, as categorias foram inseridas no software The Observer XT 7.0, seguida da inclusão dos áudios para análise. Importante destacar que a categoria procedimentos de intervenção foi inserida na seção denominada "modificadores" do Observer $X T$, de modo que foi analisada em par com as categorias de comportamento do terapeuta. Após, houve análise de 15 minutos de uma sessão selecionada aleatoriamente, via sorteio, com as observadoras analisando os áudios separadamente, com o auxí- lio do protocolo. Após a análise da concordância, as observadoras se reuniram e discutiram aspectos do protocolo, seguindo a análise de mais 15 minutos de uma sessão, totalizando quatro tentativas seguidas de reuniões até alcançar o percentual indicado. Após discussão sobre as categorias, as observadoras analisaram os áudios separadamente buscando o índice de concordância de ao menos $80 \%$, obtida através da aplicação da equação: (eventos concordantes / eventos concordantes + eventos discordantes) $\mathrm{x} 100$.

Ao atingir índice satisfatório, foram sorteadas $20 \%$ do total de sessões a serem analisadas (quatro sessões, duas de cada participante) a fim de atingir o índice de concordância satisfatório de consenso entre as observadoras. As sessões sorteadas e os índices atingidos foram: P1 (2a sessão - 91\%; $2^{\mathrm{a}}$ sessão - 90\%) e P2 ( $3^{\mathrm{a}}$ sessão $-83 \% ; 17^{\mathrm{a}}$ sessão $88 \%$ ). Foram incluídas nos resultados as sessões analisadas por uma das observadoras, descartando a análise da mesma sessão elaborada pela outra observadora. A sessão que foi analisada de forma separada de 15 em 15 minutos foi descartada. O índice alcançado foi avaliado em termos de frequência das categorias de comportamento e tema de sessão.

Depois disso, a pesquisadora terminava de categorizar as sessões faltantes. Ao término das categorizações, os dados foram analisados de acordo com o momento da intervenção: momento inicial (três sessões iniciais), momento intermediário (quatro sessões) e momento final (três sessões finais).

\section{Procedimentos de tratamento e análise de dados}

Os resultados obtidos através da aplicação e resposta dos instrumentos foram analisados através da comparação dos níveis de sintomas ansiosos/ depressivos (obtidos através da correção, seguindo a norma dos respectivos instrumentos BAI, BDI e PHQ-9) antes da intervenção, ao longo da intervenção e ao término da mesma, sendo considerados como resultados de produto da intervenção comportamental. O Roteiro de Entrevista Clínica foi estudado a partir da análise de conteúdo, de forma que foi possível descrever as queixas iniciais de cada cliente, além de descrever as queixas similares apresentadas pelas duas clientes e os objetivos atingidos ao final da intervenção terapêutica. 
Para a análise estatística da frequência e duração dos comportamentos avaliados durante as sessões de intervenção, foi adotado o seguinte procedimento. Após a categorização das gravações de áudio no software The Observer XT 7.0, foram geradas planilhas com duração e frequência de cada comportamento das clientes e das terapeutas. Essas planilhas foram organizadas em categorias previamente definidas. Na sequência, os dados foram transcritos para o software IBM SPSS Statistics, onde foram realizados testes estatísticos (Mann-Whitney e Kruskal-Wallis) para cada uma das participantes e terapeutas. O teste MannWhitney foi utilizado para comparar a ocorrência das categorias entre as díades. Já o Kruskal-Wallis foi utilizado para comparar a ocorrência das categorias entre os momentos, dividindo os processos terapêuticos nos momentos inicial (média de três sessões por díade entre as dez primeiras), intermediário (média de quatro sessões por díade entre as dez medianas) e final (média de três sessões entre as dez últimas). Os resultados foram organizados na forma de tabelas e considerado o nível de significância de $5 \%$.

\section{Resultados}

São apresentados os resultados obtidos a partir da análise dos instrumentos, como as queixas iniciais e objetivos de cada participante, os objetivos atingidos ao final do processo terapêutico de acordo com os relatos das participantes, além dos resultados obtidos através da aplicação e correção dos instrumentos BAI, BDI, PHQ-9 e IHS-Del Prette.

A Tabela 1 apresenta as queixas iniciais e objetivos Comportamentais das duas participantes obtidas através do Roteiro de Entrevista Clínica.

De acordo com a Tabela 1, a sintomatologia de ansiedade e depressão se apresenta nos dois casos, haja vista que era critério para participação no estudo. Apresentaram similaridades quanto a demanda pelo treino de comunicação em três áreas de interação social: laboral, conjugal e parental. As duas participantes apresentavam dificuldades em negociar as atividades domésticas, sendo P1 com o marido e P2 com o filho. Como reserva comportamental em comum, as duas clientes apresentavam comportamento de responsabilidade quanto ao âmbito laboral e buscavam por auxílio na área da saúde, quando necessário. No relato das participantes, no Pós-teste e Seguimento, todas as queixas que as levaram a procura pelo atendimento, foram superadas.

Tabela 1. Queixas, Dificuldades e Objetivos apresentados pelas participantes.

\begin{tabular}{|c|c|c|}
\hline Participante & $\begin{array}{l}\text { Queixas, dificuldades e objetivos específicos de cada } \\
\text { cliente }\end{array}$ & $\begin{array}{l}\text { Queixas, dificuldades e objetivos seme- } \\
\text { lhantes entre as duas clientes }\end{array}$ \\
\hline \multirow{4}{*}{ P1 } & $\begin{array}{l}\text { Emissão frequente de comportamento não assertivo e agres- } \\
\text { sivo }\end{array}$ & Sintomatologia de ansiedade e depressão \\
\hline & Dificuldade para negociar tarefas de casa com o marido & $\begin{array}{l}\text { Déficit em habilidades sociais no âmbito } \\
\text { profissional }\end{array}$ \\
\hline & Dificuldade de interação com os colegas de trabalho & Déficit em habilidades sociais conjugais \\
\hline & Desenvolveu a auto-regra de não ser uma boa mãe & Déficit em habilidades educativas parentais \\
\hline \multirow{4}{*}{ P2 } & $\begin{array}{l}\text { Considera o marido autoritário, tem dificuldade de conversar } \\
\text { com ele, principalmente sobre a questão financeira da família, } \\
\text { que se encontra com muitas dívidas em nome de P2 }\end{array}$ & Promover autoconhecimento e autocontrole \\
\hline & Dificuldade de solicitar auxílio do filho com as tarefas de casa & \\
\hline & $\begin{array}{l}\text { Dificuldade em iniciar e manter conversações, solicitar mudan- } \\
\text { ça de comportamento, autocontrole e comunicação assertiva, } \\
\text { expressar sentimentos positivos e dar feedback positivo e } \\
\text { feedback negativo }\end{array}$ & \\
\hline & Baixa autoestima e dificuldade de discriminar suas qualidades & \\
\hline
\end{tabular}


Tabela 2. Indicadores de saúde mental das participantes nas diferentes fases do delineamento, de acordo com os instrumentos BAI, BDI e PQH-9.

\begin{tabular}{l|c|c|c|c|c|c|c|c}
\hline \multicolumn{2}{c}{ P1 } & \multicolumn{7}{c}{ P2 } \\
\hline & Pré & Intermediária & Pós & Seguimento & Pré & Intermediária & Pós & Seguimento \\
\hline BAI & $32 \mathrm{C}$ & $15 \mathrm{NC}$ & $12 \mathrm{NC}$ & $04 \mathrm{NC}$ & $29 \mathrm{C}$ & $25 \mathrm{C}$ & $19 \mathrm{NC}$ & $19 \mathrm{NC}$ \\
\hline BDI & $22 \mathrm{C}$ & $10 \mathrm{NC}$ & $07 \mathrm{NC}$ & $01 \mathrm{NC}$ & $29 \mathrm{C}$ & $20 \mathrm{C}$ & 07NC & $18 \mathrm{NC}$ \\
\hline PHQ-9 & $22 \mathrm{C}$ & $06 \mathrm{NC}$ & $03 \mathrm{NC}$ & $04 \mathrm{NC}$ & $18 \mathrm{C}$ & 09NC & 08NC & 09NC \\
\hline
\end{tabular}

NC - Não Clínico

C - Clínico

Tabela 3. Indicadores do IHS - Del Prette

\begin{tabular}{|c|c|c|c|c|c|}
\hline & & PRÉ-TESTE & INTERMEDIÁRIO & PÓS-TESTE & SEGUIMENTO \\
\hline \multirow{2}{*}{ FATOR 1 (11 itens) } & $\mathrm{P} 1$ & 12 & 16 & 15 & 13 \\
\hline & P2 & 6 & 6 & 14 & 12 \\
\hline \multirow{2}{*}{ FATOR 2 (7 itens) } & $\mathrm{P} 1$ & 14 & 21 & 10 & 16 \\
\hline & P2 & 16 & 12 & 15 & 12 \\
\hline \multirow{2}{*}{ FATOR 3 (7 itens) } & P1 & 2 & 12 & 7 & 17 \\
\hline & $\mathrm{P} 2$ & 8 & 13 & 17 & 16 \\
\hline \multirow{2}{*}{ FATOR 4 (3 itens) } & $\mathrm{P} 1$ & 3 & 6 & 8 & 8 \\
\hline & $\mathrm{P} 2$ & 3 & 3 & 8 & 4 \\
\hline \multirow{2}{*}{ FATOR 5 (3 itens) } & $\mathrm{P} 1$ & 7 & 5 & 8 & 5 \\
\hline & $\mathrm{P} 2$ & 6 & 7 & 8 & 6 \\
\hline \multirow{2}{*}{ ESCORE TOTAL } & $\mathrm{P} 1$ & 38 & 60 & 48 & 61 \\
\hline & $\mathrm{P} 2$ & 39 & 41 & 62 & 50 \\
\hline
\end{tabular}

As Tabelas 2 e 3 apresentam índices de saúde mental das duas participantes nas diferentes fases da pesquisa.

Considerando a Tabela 2, P1 passou de nível moderado de ansiedade no Pré-teste para nível leve ao longo da Medida Intermediária e Pós-teste, de forma que passou de clínica para não clínica. No Seguimento, a participante apresentou níveis mínimos de ansiedade; P1 apresentou nível moderado de depressão e indicadores de presença de depressão maior severa no Pré-teste, sendo o quadro revertido de acordo com BDI e PHQ-9, ao longo do tratamento e se confirmando no Seguimento, visto que apontou escores não clínicos na avaliação do Pós-teste ao Seguimento.

P2 iniciou o tratamento com níveis moderados de ansiedade e depressão, e indicadores de depressão maior leve no Pré-teste, de acordo com os instrumentos BAI e BDI, os sintomas de ansiedade e depressão passaram a leve, e de acordo com o PHQ-9, os indicadores de depressão maior leve se mantiveram no Seguimento, embora o escore tenha 
diminuído ao longo do processo terapêutico; assim, a cliente apresentou escore clínico no Pré-teste e Pós-teste, passando a não clínico no Pós-teste e Seguimento, nos três instrumentos.

De acordo com a Tabela 3 verificou-se que P1 já tinha bom repertório de habilidades sociais nos Fatores 1 (Enfrentamento e Auto-afirmação com risco) e 2 (Auto - afirmação na expressão de sentimentos positivos), os quais se mantiveram altos no decorrer das avaliações; destaca-se que para esses fatores houve aumento na avaliação intermediária (metade do período letivo), mas os escores reduziram no Pós-teste e Seguimento ficando com valores próximos à linha de base, contudo, interessante ressaltar que houve avanço no item 28 - Elogiar familiares, pertencente ao Fator 2, evidenciando um ganho ao longo do processo terapêutico, já que se comunicar de forma não agressiva, assertiva foi um dos objetivos iniciais, cumpridos. Para P1 os fatores 3 e 4, Conversação e Desenvoltura Social e AutoExposição a desconhecidos e situações novas, tinham maior grau de dificuldade com escores baixos no Pré-teste, os quais aumentaram no decorrer na intervenção, com manutenção ou ainda melhora no Seguimento, por exemplo, o aumento do escore em vários itens inclusos no Fator 3, a saber: 17. Encerrar conversação, 37. Pedir favores a colegas, 36. Manter conversação, 22. Recusar pedidos abusivos e 19. Abordar autoridade, fato que também pode evidenciar um ganho obtido a partir do treino de habilidades sociais, que se concentrou em ensinar a comunicação assertiva, pois a cliente descreve que melhorou a comunicação com o filho, relatou que conseguia solicitar mudanças de comportamento de forma assertiva e o filho atendia ao pedido, por exemplo, para arrumar seu quarto. O Fator 5 (Autocontrole da agressividade) apresentava escore médio no início da intervenção, o qual teve pouca variação nas demais medidas. $\mathrm{O}$ escore total no Seguimento foi de 61 .

P2 apresentava bom repertório do Fator 2 (Auto-afirmação na expressão de sentimentos positivos), cujos valores tiveram pouca alteração no decorrer das avaliações. Os Fatores 1 e 3 (Enfrentamento e Auto-afirmação com risco e Conversação e Desenvoltura Social) apresentaram escores baixos no início da intervenção, os quais dobraram de valor após intervenção, com manutenção no Seguimento, por exemplo, o item 07 apresentar-se para outra pessoa, incluso no Fator 1, que obteve maiores escores no Pós-teste e foi mantido no Seguimento. Já os Fatores 4 (Auto Exposição a desconhecidos e situações novas) e 5 (Autocontrole da agressividade), com baixos escores no início, tiveram pouco aumento nas demais medidas e no Seguimento os escores foram iguais ou próximos ao Pré-teste. O escore total da $\mathrm{P} 2$ no Seguimento foi de 50.

As tabelas que seguem descrevem os resultados relacionados à interação terapêutica tratados estatisticamente, contendo as médias de ocorrências de todas as categorias, em termos de frequência (Tabela 4) e duração (Tabela 5), e os valores de $p$ do teste Mann-Whitney que verificou a existência de diferenças estatísticas entre as díades, quanto às categorias de análise. Categorias em negrito destacam as diferenças estatísticas $(p<0,05)$ entre as díades.

De acordo com as Tabelas 4 e 5, verifica-se que, para a $\mathrm{P} 1$, as categorias do terapeuta mais frequentes foram facilitação, solicitação de relato, solicitação de reflexão e aprovação e enquanto duração foram informação, solicitação de relato, solicitação de reflexão e aprovação. Já para a $\mathrm{P} 2$ a frequência foi maior para facilitação, solicitação de relato, solicitação de reflexão, empatia, informação e aprovação; quanto a duração todas as categorias ocorreram com escores altos, muito superiores às da P1 (informação, solicitação de relato, solicitação de reflexão, aprovação, recomendação, empatia). As comparações estatísticas demonstraram que as categorias do comportamento de terapeuta diferenciaram as clientes, seja em frequência, seja em duração com maiores médias para P2.

Quanto aos comportamentos das clientes, destacam-se tanto em frequência quanto em duração, os comportamentos de relato, estabelece relações, melhora, autocontrole/autoconhecimento e queixas e dificuldades. Tanto em frequência quanto em duração a ocorrência foi diferente para as clientes em relato, melhora e autocontrole/autoconhecimento. No entanto, diferente do visto no comportamento do terapeuta, os relatos de melhora e de autocontrole/autoconhecimento foram mais frequentes para P1 que para P2. 
Tabela 4 . Médias e valores de $p$ de acordo com o teste de Mann-Whitney para a comparação das díades em termos de frequência

\begin{tabular}{|c|c|c|c|c|c|c|c|c|c|c|c|c|c|c|c|}
\hline $\begin{array}{l}\text { Categorias da } \\
\text { terapeuta }\end{array}$ & $\begin{array}{l}\text { Média } \\
\text { P1 }\end{array}$ & $\begin{array}{l}\text { Média } \\
\text { P2 }\end{array}$ & $\begin{array}{l}\text { Valor } \\
\text { de } p\end{array}$ & $\begin{array}{l}\text { Categorias } \\
\text { da cliente }\end{array}$ & $\begin{array}{l}\text { Média } \\
\text { P1 }\end{array}$ & $\begin{array}{l}\text { Média } \\
\text { P2 }\end{array}$ & $\begin{array}{l}\text { Valor } \\
\text { de } p\end{array}$ & Procedimentos & $\begin{array}{l}\text { Média } \\
\text { P1 }\end{array}$ & $\begin{array}{l}\text { Média } \\
\text { P2 }\end{array}$ & $\begin{array}{l}\text { Valor } \\
\text { de } p\end{array}$ & Temas & $\begin{array}{l}\text { Média } \\
\text { P1 }\end{array}$ & $\begin{array}{l}\text { Média } \\
\text { P2 }\end{array}$ & $\begin{array}{l}\text { Valor } \\
\text { de } p\end{array}$ \\
\hline Facilitação & 23,5 & 53,5 & 0,045 & Relato & 15,2 & 28,7 & 0,002 & Análise funcional & 11,8 & 26 & 0,005 & $\begin{array}{l}\text { Relações Filhos } \\
\text { Enteados }\end{array}$ & 1,9 & 0 & 0,001 \\
\hline $\begin{array}{l}\text { Solicitação de } \\
\text { relato }\end{array}$ & 11,9 & 24 & 0,011 & $\begin{array}{l}\text { Estabelece } \\
\text { relações }\end{array}$ & 4,6 & 6,5 & 0,494 & Ref. diferencial & 2,3 & 4 & 0,231 & $\begin{array}{l}\text { Relações } \\
\text { Cônjuge }\end{array}$ & 1,7 & 0,1 & 0,005 \\
\hline $\begin{array}{l}\text { Solicitação de } \\
\text { reflexão }\end{array}$ & 7,3 & 11,3 & 0,074 & Melhora & 2,5 & 0,3 & 0,004 & Instrução & 0,7 & 0,5 & 0,584 & $\begin{array}{l}\text { Conversações } \\
\text { Cônjuge }\end{array}$ & 1,5 & 0,4 & 0,062 \\
\hline Aprovação & 4 & 5,3 & 0,674 & $\begin{array}{l}\text { Autocontrole/ } \\
\text { autoconheci- } \\
\text { mento }\end{array}$ & 2,4 & 0,7 & 0,013 & Modelo & 0,4 & 0,7 & 0,375 & $\begin{array}{l}\text { Conversações } \\
\text { Filhos }\end{array}$ & 1,3 & 0 & 0,001 \\
\hline Informação & 2,3 & 5,7 & 0,027 & $\begin{array}{l}\text { Queixas e } \\
\text { dificuldades }\end{array}$ & 1,4 & 2,2 & 0,209 & Instrumentos & 0,1 & 0 & 0,317 & $\begin{array}{l}\text { Trabalho } \\
\text { Estudo Carreira }\end{array}$ & 1,2 & 0,8 & 0,618 \\
\hline Empatia & 1,4 & 6,5 & 0,001 & Solicitação & 0,7 & 0,9 & 0,233 & Role-playing & 0 & 0,4 & 0,068 & $\begin{array}{l}\text { Conversações } \\
\text { Trabalho }\end{array}$ & 0,7 & 0,5 & 0,831 \\
\hline Recomendação & 1,4 & 4 & 0,03 & Concordância & 0,3 & 0,4 & 0,358 & Auto-revelação & 0 & 0,8 & 0,03 & $\begin{array}{l}\text { Sentimento } \\
\text { Negativo } \\
\text { Cônjuge }\end{array}$ & 0,7 & 0,1 & 0,021 \\
\hline Interpretação & 1,4 & 8 & 0,001 & $\begin{array}{l}\text { Outras } \\
\text { vocalizações } \\
\text { cliente }\end{array}$ & 0,3 & 0,2 & 0,615 & & & & & $\begin{array}{l}\text { Sentimento } \\
\text { Negativo Filhos }\end{array}$ & 0,2 & 0 & 0,146 \\
\hline $\begin{array}{l}\text { Outras } \\
\text { vocalizações } \\
\text { terapeuta }\end{array}$ & 0,6 & 3,5 & 0,008 & $\begin{array}{l}\text { Silêncio } \\
\text { cliente }\end{array}$ & 0,1 & 0,9 & 0,234 & & & & & $\begin{array}{l}\text { Fazer e } \\
\text { Recusar Pedido } \\
\text { Cônjuge }\end{array}$ & 0,2 & 0,2 & 1 \\
\hline $\begin{array}{l}\text { Silêncio } \\
\text { terapeuta }\end{array}$ & 0,1 & 0,2 & 0,542 & Oposição & 0 & 0,1 & 0,317 & & & & & $\begin{array}{l}\text { Queixas/ } \\
\text { Sintomas } \\
\text { Psiquiátricos }\end{array}$ & 0,1 & 0,5 & 0,121 \\
\hline \multirow[t]{11}{*}{ Reprovação } & 0 & 0,1 & 0,317 & & & & & & & & & $\begin{array}{l}\text { Conversações } \\
\text { Amigos/ } \\
\text { Colegas }\end{array}$ & 0,1 & 0 & 0,317 \\
\hline & & & & & & & & & & & & $\begin{array}{l}\text { Sentimento } \\
\text { Positivo } \\
\text { Amigos/ } \\
\text { Colegas }\end{array}$ & 0,1 & 0 & 0,317 \\
\hline & & & & & & & & & & & & $\begin{array}{l}\text { Sentimento } \\
\text { Negativo } \\
\text { Trabalho }\end{array}$ & 0,1 & 0 & 0,317 \\
\hline & & & & & & & & & & & & $\begin{array}{l}\text { Fazer e } \\
\text { Recusar Pedido } \\
\text { Filhos }\end{array}$ & 0,1 & 0,1 & 1 \\
\hline & & & & & & & & & & & & Outros Temas & 0,1 & 0,1 & 1 \\
\hline & & & & & & & & & & & & $\begin{array}{l}\text { Relação tera- } \\
\text { pêutica }\end{array}$ & 0 & 0,3 & 0,147 \\
\hline & & & & & & & & & & & & $\begin{array}{l}\text { Sentimentos, } \\
\text { julgamentos } \\
\text { e tendência à } \\
\text { ação }\end{array}$ & 0 & 0,3 & 0,067 \\
\hline & & & & & & & & & & & & $\begin{array}{l}\text { Relações } \\
\text { Outros } \\
\text { Familiares }\end{array}$ & 0 & 0,2 & 0,317 \\
\hline & & & & & & & & & & & & $\begin{array}{l}\text { Conversações } \\
\text { Familiares }\end{array}$ & 0 & 0,1 & 0,317 \\
\hline & & & & & & & & & & & & $\begin{array}{l}\text { Comunicação } \\
\text { Amigos/ } \\
\text { Colegas }\end{array}$ & 0 & 0,2 & 0,317 \\
\hline & & & & & & & & & & & & Crítica Trabalho & 0 & 0,1 & 0,317 \\
\hline
\end{tabular}


Tabela 5. Médias e valores de $\mathrm{p}$ de acordo com o teste de Mann-Whitney para a comparação das díades em termos de duração

\begin{tabular}{|c|c|c|c|c|c|c|c|c|c|c|c|c|c|c|c|}
\hline $\begin{array}{l}\text { Categorias da } \\
\text { terapeuta }\end{array}$ & $\begin{array}{l}\text { Média } \\
\text { P1 }\end{array}$ & $\begin{array}{l}\text { Média } \\
\text { P2 }\end{array}$ & $\begin{array}{l}\text { Valor } \\
\text { de } p\end{array}$ & $\begin{array}{l}\text { Categorias } \\
\text { da cliente }\end{array}$ & $\begin{array}{l}\text { Média } \\
\text { P1 }\end{array}$ & $\begin{array}{l}\text { Média } \\
\text { P2 }\end{array}$ & $\begin{array}{l}\text { Valor } \\
\text { de } p\end{array}$ & Procedimentos & $\begin{array}{l}\text { Média } \\
\text { P1 }\end{array}$ & $\begin{array}{l}\text { Média } \\
\text { P2 }\end{array}$ & $\begin{array}{l}\text { Valor } \\
\text { de } p\end{array}$ & Temas & $\begin{array}{l}\text { Média } \\
\text { P1 }\end{array}$ & $\begin{array}{l}\text { Média } \\
\text { P2 }\end{array}$ & $\begin{array}{l}\text { Valor } \\
\text { de } p\end{array}$ \\
\hline Informação & 77,9 & 518,9 & 0,015 & Relato & 2944 & 1509 & 0,016 & $\begin{array}{l}\text { Análise fun- } \\
\text { cional }\end{array}$ & 65,8 & 709,6 & 0,000 & $\begin{array}{l}\text { Relações } \\
\text { Filhos } \\
\text { Enteados }\end{array}$ & 538,7 & 35,3 & 0,004 \\
\hline $\begin{array}{l}\text { Solicitação de } \\
\text { relato }\end{array}$ & 55,1 & 175,2 & 0,001 & $\begin{array}{l}\text { Estabelece } \\
\text { relações }\end{array}$ & 197,4 & 205,4 & 0,94 & Ref. diferencial & 22,8 & 93,7 & 0,094 & $\begin{array}{l}\text { Conversações } \\
\text { Trabalho }\end{array}$ & 419,3 & 670,1 & 0,716 \\
\hline $\begin{array}{l}\text { Solicitação de } \\
\text { reflexão }\end{array}$ & 52,7 & 413 & 0,003 & Melhora & 122,5 & 4,44 & 0,006 & Instrução & 13,8 & 54,4 & 0,967 & $\begin{array}{l}\text { Trabalho, } \\
\text { Estudo e/ou } \\
\text { Carreira }\end{array}$ & 371,7 & 260,9 & 0,679 \\
\hline Aprovação & 36,6 & 153,6 & 0,023 & $\begin{array}{l}\text { Autocontrole/ } \\
\text { autoconheci- } \\
\text { mento }\end{array}$ & 90,4 & 21,2 & 0,01 & Instrumentos & 5 & 0 & 0,317 & $\begin{array}{l}\text { Relações } \\
\text { Cônjuge }\end{array}$ & 330,4 & 128,1 & 0,024 \\
\hline Recomendação & 28,1 & 292,1 & 0,014 & $\begin{array}{l}\text { Queixas e } \\
\text { dificuldades }\end{array}$ & 74,4 & 63,6 & 0,44 & Modelo & 2,6 & 35 & 0,192 & $\begin{array}{l}\text { Conversações } \\
\text { Filhos }\end{array}$ & 276,7 & 0 & 0,001 \\
\hline Interpretação & 26,2 & 350,8 & 0,000 & Solicitação & 13,5 & 8,2 & 0,383 & Role-playing & 0 & 30,6 & 0,068 & $\begin{array}{l}\text { Conversações } \\
\text { Cônjuge }\end{array}$ & 254,9 & 0 & 0,002 \\
\hline Empatia & 13,6 & 206,3 & 0,000 & $\begin{array}{l}\text { Outras } \\
\text { vocalizações } \\
\text { cliente }\end{array}$ & 12,9 & 3 & 0,427 & Auto-revelação & 0 & 37,9 & 0,031 & $\begin{array}{l}\text { Sentimento } \\
\text { Negativo } \\
\text { Cônjuge }\end{array}$ & 174,9 & 91,5 & 0,088 \\
\hline $\begin{array}{l}\text { Outras } \\
\text { vocalizações } \\
\text { terapeuta }\end{array}$ & 11,1 & 160,5 & 0,002 & $\begin{array}{l}\text { Silêncio } \\
\text { cliente }\end{array}$ & 5,1 & 11,2 & 0,304 & & & & & $\begin{array}{l}\text { Fazer e } \\
\text { Recusar } \\
\text { Pedido } \\
\text { Cônjuge }\end{array}$ & 29,3 & 164,8 & 0,914 \\
\hline $\begin{array}{l}\text { Silêncio tera- } \\
\text { peuta }\end{array}$ & 5 & 1,6 & 0,627 & Concordância & 3,1 & 0,9 & 0,358 & & & & & $\begin{array}{l}\text { Conversações } \\
\text { Amigos/ } \\
\text { Colegas }\end{array}$ & 20,4 & 0 & 0,317 \\
\hline \multirow[t]{12}{*}{ Reprovação } & 0 & 5,2 & 0,317 & Oposição & 0 & 1 & 0,317 & & & & & $\begin{array}{l}\text { Sentimento } \\
\text { Negativo Filhos }\end{array}$ & 19,1 & 0 & 0,147 \\
\hline & & & & & & & & & & & & $\begin{array}{l}\text { Sentimento } \\
\text { Negativo } \\
\text { Trabalho }\end{array}$ & 13,8 & 0 & 0,317 \\
\hline & & & & & & & & & & & & Outros Temas & 12,5 & 12 & 0,942 \\
\hline & & & & & & & & & & & & $\begin{array}{l}\text { Fazer e } \\
\text { Recusar } \\
\text { Pedido Filhos }\end{array}$ & 11,5 & 36,4 & 0,942 \\
\hline & & & & & & & & & & & & $\begin{array}{l}\text { Sentimento } \\
\text { Positivo } \\
\text { Amigos/ } \\
\text { Colegas }\end{array}$ & 3,9 & 0 & 0,317 \\
\hline & & & & & & & & & & & & $\begin{array}{l}\text { Queixas/ } \\
\text { Sintomas } \\
\text { Psiquiátricos }\end{array}$ & 2,8 & 306,3 & 0,091 \\
\hline & & & & & & & & & & & & $\begin{array}{l}\text { Relação tera- } \\
\text { pêutica }\end{array}$ & 0 & 39,2 & 0,147 \\
\hline & & & & & & & & & & & & $\begin{array}{l}\text { Sentimentos, } \\
\text { julgamentos } \\
\text { e tendência à } \\
\text { ação }\end{array}$ & 0 & 129 & 0,068 \\
\hline & & & & & & & & & & & & $\begin{array}{l}\text { Relações } \\
\text { Outros } \\
\text { Familiares }\end{array}$ & 0 & 369,5 & 0,031 \\
\hline & & & & & & & & & & & & $\begin{array}{l}\text { Conversações } \\
\text { Familiares }\end{array}$ & 0 & 89,2 & 0,317 \\
\hline & & & & & & & & & & & & $\begin{array}{l}\text { Comunicação } \\
\text { Amigos/ } \\
\text { Colegas }\end{array}$ & 0 & 19,8 & 0,317 \\
\hline & & & & & & & & & & & & $\begin{array}{l}\text { Crítica } \\
\text { Trabalho }\end{array}$ & 0 & 190,7 & 0,317 \\
\hline
\end{tabular}


Quanto aos procedimentos utilizados, pelas terapeutas destaca-se, em frequência e duração, a análise funcional seguida de reforço diferencial, instrução e modelo. Com P2 foi utilizado também role-playing e auto revelação. Novamente a análise funcional, outras técnicas e auto revelação ocorreram mais com $\mathrm{P} 2$.

Os temas das sessões estão de acordo com as queixas iniciais e versam especialmente sobre relacionamento conjugal, com filhos e no trabalho. E para P2 o tema relações com outros familiares (pais, irmãos) ocorreu com duração alta. Para P1 os temas com mais frequência e duração foram: relações com filhos/enteados, conversações no trabalho, trabalho, estudo e/ou carreira, relações conjugais, conversações com filhos e cônjuge e expressão de sentimentos negativos ao cônjuge. Para P2 a maior ocorrência, em frequência e duração, foi para temas relacionados ao trabalho, seguido do relacionamento conjugal e filhos. Confirmouse estatisticamente que com P1 foram trabalhados mais assuntos/comportamentos relacionados à família e que os comportamentos relacionados ao trabalho foram igualmente discutidos com as clientes. Quanto aos operantes ensinados para as clientes houve o destaque para comunicação e expressão de sentimento negativo, ainda que outros comportamentos tenham também sido trabalhados com menor frequência/duração igualmente entre as clientes: conversações com amigos, expressão de sentimentos negativos para filhos e trabalho, fazer e recusar pedidos para cônjuge e filhos, lidar com críticas, queixas/sintomas psiquiátricos, críticas no trabalho.

É possível constatar que P2 iniciou o processo terapêutico com maior diversidade de queixas em comparação a P1, como dificuldades em diferentes aspectos de comunicação e problemas relacionados à baixa autoestima, além da dificuldade em discriminar aspectos positivos das interações sociais. De acordo com a medida de relato, as categorias Melhora e Autocontrole/autoconhecimento foram mais frequentes para $\mathrm{P} 1$ que para $\mathrm{P} 2$, o que indica uma melhora evidente para P1 quanto a esses repertórios. Apesar da diferença, ambas as clientes terminaram a intervenção ( 9 meses) com medidas não clínicas para ansiedade e depressão.

\section{Discussão}

O presente estudo teve por objetivo descrever comportamentos e procedimentos de intervenção analítico-comportamental com mulheres que apresentavam comorbidade de ansiedade e depressão, por meio de um delineamento de sujeito único (Kazdin, 1992; Matos, 1990). O estudo demonstrou aquisição comportamental e redução de sintomas, sugerindo evidências de melhora ao final do processo terapêutico. Além disso, a partir dos resultados pode-se observar que foram dispensados tratamentos de acordo com a demanda, considerando o repertório de entrada das participantes (Matos, 1990), e garantindo a aplicação de TAC (Abreu \& Abreu, 2017; De-Farias, 2010).

A idiossincrasia prevista na TAC foi constatada pelas diferenças em ocorrência e duração dos comportamentos de terapeutas e clientes (Zamignani \& Andery, 2005), bem como nos procedimentos utilizados e nos temas trabalhados com cada cliente. No entanto, foi possível notar alguma regularidade também, como previsto na ciência comportamental (Skinner, 1953), o que pode auxiliar no tratamento de mulheres com ansiedade e depressão. Nesse sentido, verificou-se que as duas clientes tinham queixas interpessoais quanto à família e trabalho e, por isso, os comportamentos de comunicação e de expressividade foram os mais abordados. Destaca-se que o foco das sessões foi na resolução de problemas interpessoais (família e trabalho) e que as intervenções, por um lado, eram pautadas na formulação do caso e, por outro, no relato espontâneo das clientes, incluindo os das tarefas de casa, o que implicava em ensinar os operantes alvos contingentes aos problemas e queixas relatados. Desse modo, foi observada melhora para as queixas relatadas e trabalhadas na terapia em termos de comportamentos-alvo de intervenção, as quais eram relativas aos quadros de ansiedade e de depressão; os resultados se mantiveram na avaliação de Seguimento. Além das queixas relatadas pelas clientes, verificou-se com o IHS-Del Prette que o Fator 3 (Conversação e Desenvoltura Social) foi o que teve melhores resultados após a intervenção, uma vez que foi o foco da intervenção, considerando as demandas das participantes. 
Pode-se afirmar que P1 e P2 iniciaram o processo terapêutico com um quadro de comportamentos considerados ansiosos e depressivos, de acordo com o relato e pelos escores obtidos nos instrumentos aplicados na fase de Pré-teste. Ao considerar o histórico de tratamento anterior, constatou-se que já estavam em tratamento medicamentoso há pelo menos sete anos e ainda apresentavam os sintomas, concordando com a literatura encontrada quanto aos comprometimentos funcionais (Johanson et al., 2013; Starr et al., 2014) e destacando dificuldades em relação ao prognóstico das pessoas com ansiedade e depressão (Araújo et al., 2010 ; Newby et al.; 2013). Importante destacar que as participantes continuaram o tratamento com a medicação ao longo do processo terapêutico, variável que já se apresentava na fase de Pré-teste em paralelo com os sintomas apresentados.

Considerando pertinente avaliar medidas de processo, além das de resultado (Braga \& Vandenberghe, 2006; Shinohara, 2000; Zamignani \& Meyer, 2007) foram conduzidas descrições e análises quanto aos comportamentos das clientes, terapeutas e procedimentos. Os dados quanto à P1 indicaram que as categorias Relato e Estabelece Relações predominaram, em termos de frequência e duração, e que a categoria Melhora destacou-se em duração, de forma que o próprio relato da participante foi ao encontro dos escores obtidos através das correções dos instrumentos. As categorias da terapeuta que se apresentaram com maior frequência foram facilitação, solicitação de relato, solicitação de reflexão e aprovação; já em termos de duração, as categorias recomendação, informação e aprovação também foram destaques. As categorias comportamentais de terapeutas e clientes concordaram, em parte, com Garcia et al. (2017) que também verificaram, em universitários com fobia social (duas mulheres e um homem), ser os comportamentos de facilitação e concordância do terapeuta os mais frequentes. Em Garcia et al. (2017) também o tema mais trabalhado foi sobre relações interpessoais, especialmente nas interações com parceiros amorosos. Na presente investigação destacaram-se também solicitação de reflexão e aprovação quanto ao repertório das terapeutas e de comportamentos de relato, de estabelecimento de relações, de melhora e de autoconhecimento/autocontrole das clientes, tal como verificado em Orti et al. (2015) no atendimento a mães de escolares com problemas de internalização.

A categoria Reprovação (terapeuta) não apareceu na díade 1, e a sua ocorrência na díade 2 foi bastante pontual e inexpressiva. Isso converge com o princípio de minimizar a estimulação aversiva do contexto terapêutico, garantindo uma escuta predominantemente não-punitiva, tanto quanto for possível (Zamignani \& Meyer, 2007). A baixa frequência e duração de respostas de oposição, por parte das duas clientes, contribuem para demonstrar essa dimensão não-punitiva do tratamento para as clientes.

A descrição das interações terapeutas-clientes associada às queixas e resultados obtidos quanto às superações, permite hipotetizar que as terapeutas emitiram respostas contingentes aos comportamentos das clientes (Ruiz-Sancho e cols., 2013; Silveira \& Kerbauy, 2000) e à formulação dos casos (Abreu \& Abreu, 2017). Quanto às práticas de intervenção utilizadas, a análise funcional e o reforçamento diferencial foram os destaques para essa cliente, evidenciando que a análise funcional é o principal recurso de avaliação e de intervenção do terapeuta comportamental (Abreu \& Abreu, 2017).

Ao analisar os dados relacionados à P2, pôde-se observar que as categorias Relato, Estabelece Relações e Queixas e Dificuldades predominaram no comportamento da participante, em termos de frequência e duração, destacando-se a categoria Queixas e Dificuldades. As categorias da terapeuta 2 que se apresentaram com maior frequência foram Facilitação e Solicitação de Relato, e as categorias Solicitação de Reflexão, Recomendação, Informação, Interpretação e Sumarização se destacaram em termos de duração. Análise funcional e reforçamento diferencial do comportamento alvo foram as que mais ocorreram em frequência e duração (Abreu \& Abreu, 2017).

Ao analisar os resultados de frequência e duração das categorias de comportamentos das terapeutas, observou-se que houve maior diversidade de categorias da terapeuta 2, favorecendo a hipótese de que o repertório de entrada da $\mathrm{P} 2$, com maior dificuldades, exigiu maior diversidade no manejo desta terapeuta. O estudo de Orti et al. (2015) também verificou que a ocorrência de respostas do terapeu- 
ta diferia estatisticamente, em algumas categorias da interação terapêutica, de acordo com o cliente, indicando o ajuste necessário da intervenção para cada um dos clientes.

Os achados relacionados à intervenção proposta no presente estudo, em que a análise funcional se destacou em termos de frequência e duração nos dois casos, está em acordo com os pressupostos da clínica comportamental (Abreu \& Abreu, 2017), que aponta a análise funcional como a ferramenta do analista do comportamento, tanto na fase de avaliação quanto de intervenção; além de possibilitar que o cliente compreenda as contingências a que responde, auxiliando no processo de autoconhecimento (Del Prette \& Almeida; 2012) e autocontrole. A análise funcional apareceu neste estudo principalmente em associação com as categorias de comportamento do terapeuta solicitação de relato, solicitação de reflexão, interpretação e informação, que vai ao encontro dos resultados do trabalho de Garcia e Bolsoni-Silva (2015), no qual descreveram as técnicas utilizadas em atendimento bem sucedido de uma participante com diagnóstico de Transtorno de Estresse Pós Traumático, e as técnicas mais utilizadas foram fazer perguntas e/ou descrever relações funcionais.

Conforme Shinohara (2000), a mudança no cenário da terapia comportamental levou a importância de o contexto terapêutico ser considerado, além da habilidade de aplicar técnicas do terapeuta, enfatizando a interação terapêutica. Considerando a descrição de Zamignani e Meyer (2007) para o termo "interação terapêutica", na qual considera-se a influência de comportamento do terapeuta sobre o cliente e vice versa, em fluxo de interações, pode-se afirmar que o presente estudo buscou analisar as categorias de comportamento de terapeuta e cliente, ao longo do processo terapêutico, permitindo a descrição de regularidade e de singularidades, que pode auxiliar a orientar terapeutas comportamentais no tratamentos desses quadros.

Além disso, é importante destacar que na interação, o terapeuta também sofre influência ao interagir com o cliente, sendo necessária especial atenção, haja vista que o comportamento do terapeuta pode ser avaliado como um dos fatores responsáveis para o desfecho do processo terapêutico (Shinohara; 2000; Braga \& Vandenberghe; 2006), assim, justifica-se a importância de estudos sobre os comportamentos emitidos pelo terapeuta. Dentre os encontrados na literatura, pode-se citar o estudo de Zamignani e Andery (2005) que em semelhança do descrito neste trabalho, foi composto por mais de uma díade terapeuta-cliente, no qual as sessões foram gravadas em áudio e categorizadas de acordo com categorias previamente estabelecidas pelo pesquisador. Esses autores ressaltaram a relevância de a intervenção ser conduzida por terapeutas diferentes, que recebiam as mesmas orientações quanto a aplicação de técnicas e supervisão dos casos. Este método mostrou-se útil também na presente pesquisa.

$\mathrm{Na}$ literatura, encontraram-se estudos em abordagens diferentes com intervenção efetiva, principalmente na Terapia Cognitivo-Comportamental (Faramarzi et al., 2008; Van Beek et al., 2013; Newby et al., 2013), na Terapia Cognitiva (Den Boer et al., 2007), e ainda relacionada à Mindfulness, Compassion-Mindfulness Therapy (C-MT) (Herman et al., 2013). Essas intervenções psicológicas ora foram destinadas para pessoas com ansiedade, ora com depressão e o único estudo encontrado que envolveu apenas mulheres foi de Faramarzi et al. (2008), com a condição específica de apresentar o quadro de infertilidade.

$\mathrm{Na}$ terapia comportamental, há pesquisas que trabalharam com casos de depressão ou de ansiedade e que também verificaram melhoras dos clientes, como o estudo de caso de uma pessoa com queixa de depressão apresentado por Dougher e Hackbert (2003) e o grupo de intervenção para pessoas com queixas relacionadas à ansiedade descrito por Chagas et al. (2013). Pode-se considerar, a partir dos escores obtidos nos instrumentos, bem como no relato verbal das participantes, que a intervenção proposta neste estudo alcançou seu objetivo. Desse modo, parece que a terapia comportamental pode ser efetiva no tratamento também de quadros em comorbidade de depressão e ansiedade. Considera-se que a presente pesquisa colabora nesta lacuna no conhecimento, ou seja, na avaliação de efetividade da TAC para quadros de comorbidade de ansiedade e depressão. No entanto, dado o número reduzido de participantes e o ensino de muitos operantes, é difícil afirmar sobre a generalização dos achados. 
O trabalho proposto atingiu os objetivos previamente estabelecidos, uma vez que as participantes finalizaram os atendimentos com escores não clínicos para ansiedade e depressão, além da aquisição de repertório de comunicação, as quais mantinham um quadro grave há pelo menos sete anos. Podem ser destacados alguns pontos fortes do estudo: (a) a escolha de duas clientes com quadro semelhante de ansiedade e depressão, com uso de medicamentos há muitos anos; (b) delineamento de sujeito único, com medidas repetidas de resultado e de processo, incluindo avaliação de seguimento; (c) a descrição da interação terapêutica e de procedimentos utilizados com cada uma das clientes; (d) o tratamento estatístico indicando regularidades e singularidades nos repertórios avaliados, seja das clientes, seja das terapeutas.

A descrição dessas regularidades e singularidades das clientes, descritos nesta investigação, pode ser útil para elaborar regras para o atendimento com essa população, no que referem a quais procedimentos, manejos terapêuticos e comportamentos/ temas que podem ser ensinados, de forma a obter resultados tanto na aquisição de repertórios, quanto na superação de sintomas. No entanto, a amostra é reduzida e o estudo é quase-experimental e, assim, destaca-se a necessidade de novos estudos na área, valendo-se de delineamento experimental. Sugerese, portanto, novas pesquisas que possam ser conduzidas em delineamento experimental de sujeito único e/ou de grupo, com número maior de participantes e isolando o ensino dos comportamentos ensinados, de maneira a verificar, processualmente, o impacto do ensino de cada um deles.

\section{Referências}

Abreu, P. R., \& Abreu, J. H. S. S. (2017). Ativação comportamental: Apresentando um protocolo integrador no tratamento da depressão. Revista Brasileira de Terapia Comportamental e Cognitiva, 19(4), 238-259.

Alves, N. N. F, \& Isidro-Marinho, G. (2010). Relação Terapêutica sob a perspectiva analítico-comportamental. In A. K. C. R. De-Farias, Análise Comportamental Clínica: aspectos teóricos e estudos de caso (pp. 66-94). São Paulo: Artmed Editora.
American Psychiatry Association (2013). Diagnostic and Statistical Manual of Mental disorders - DSM-5 (5a ed.). Washington: American Psychiatric Association.

Araújo, L. F., Ronzani, T. M., \& Lourenço, L. M. (2010). Análise da Literatura sobre a Comorbidade entre Fobia Social e Depressão. Gerais: Revista Interinstitucional de Psicologia, 3(2), 109-123.

Beck, A. T., \& Steer, R. A. (1990). Manual for the Beck Anxiety Inventory. San Antonio, TX: Psychological Corporation.

Beck, A. T., \& Steer, R. A. (1993). Beck Depression Inventory. Manual. San Antonio, TX: Psychology Corporation.

Bolsoni-Silva, A. T. (2009). Relacionamento Conjugal. Quais comportamentos são importantes? São Paulo: Suprema.

Braga, G. L. De B., \& Vandenberghe, L. (2006). Abrangência e função da relação terapêutica na terapia comportamental. Estudos de Psicologia, 23(3), 307-314.

Chagas, M. T., Guilherme, G., \& Moriyama, J. S. (2013). Intervenção clínica em grupo baseada na terapia de aceitação e compromisso: Manejo da ansiedade. Acta Comportamentalia, 21(4), 495-508.

Caballo, V. E. (2003). Manual de avaliação e treinamento das habilidades sociais. São Paulo: Santos.

Calais, S. L.; Bolsoni-Silva, A. T. (2008). Alcance e Limites das Técnicas Comportamentais: Algumas considerações. In M. R. Cavalcante (Org.). Análise do Comportamento: Avaliação e Intervenção. (pp. 15-30) São Paulo: Rocca.

Coêlho, N. L., \& Tourinho, E. Z. (2008). O Conceito de Ansiedade na Análise do Comportamento. Psicologia: Reflexão e Crítica, 21(2), 171-178.

Cunha, J. A. (2001). Manual da versão em português das Escalas Beck. São Paulo: Casa do Psicólogo. de-Farias, A. K. C. R. (2010). Por que "análise comportamental clínica”? Uma introdução ao livro. In: A. K. C. R. de-Farias, (Org.) Análise Comportamental Clínica: aspectos teóricos e estudos de caso (pp. 19. 29). São Paulo: Artmed Editora.

Del Prette, G., \& Almeida, T. A. C. (2012). O uso de técnicas na clínica analítico- comportamental. In: N. B. Borges, \& F. A. Cassas (Orgs.), Clínica 
Analítico- Comportamental: aspectos teóricos e práticos (pp. 147-159). Porto Alegre: Artmed.

Del Prette, G., \& Meyer, S. B. (2014). Categorização em terapia analítico- comportamental infantil: questões metodológicas e resultados de pesquisa. In D. R. Zamignani, \& S. B. Meyer, (Orgs.) Pesquisa de Processo em Psicoterapia: Estudos a partir do Instrumento SiMCCIT (pp. 21- 38) São Paulo: Paradigma Núcleo de Análise do Comportamento.

Del Prette, Z. A. P., \& Del Prette, A. (2001). Inventário de habilidades sociais (IHS- Del Prette): Manual de apuração e interpretação. São Paulo: Casa do Psicólogo.

Den Boer, P. C. A. M., Wiersma, D., Vaarwerk, I. T., Span, M. M., Stant, A. D., \& Van Den Bosch, R. J. (2007). Cognitive self-therapy for chronic depression and anxiety: a multi-centre randomized controlled study. Psychological Medicine, 37, 329-339. doi: 10.1017/S0033291706009214

Donadone, J. C., \& Meyer, S. B. (2014). Análise de Contingências envolvidas na orientação. In D. R. Zamignani, \& S. B. Meyer (Orgs.) Pesquisa de Processo em Psicoterapia: Estudos a partir do Instrumento SiMCCIT (pp. 79-104) São Paulo: Paradigma Núcleo de Análise do Comportamento.

Dougher, M. J., \& Hackbert, L. (2003). Uma explicação analítico-comportamental da depressão e o relato de um caso utilizando procedimentos baseados na aceitação. Revista Brasileira de Terapia Comportamental e Cognitiva, 5(2), 167-184.

Faramarzi, M., Alipor, A., Esmaelzadeh, S., Kheirkhah, F., Poladi, K., \& Pash, H. (2008). Treatment of depression and anxiety in infertile women: Cognitive behavioral therapy versus fluoxetine. Journal of Affective Disorders. 108, 159-164. doi: 10.1016/j.jad.2007.09.002

Fogaça, F. F. S., Meyer, S. B., \& Bolsoni- Silva, A. T. (2014). Intervenção Analítico Comportamental de grupo: descrevendo categorias de comportamento dos participantes. In D. R. Zamignani, \& S. B. Meyer (Orgs.) Pesquisa de Processo em Psicoterapia: Estudos a partir do Instrumento SiMCCIT (pp. 39- 56) São Paulo: Paradigma Núcleo de Análise do Comportamento.

Garcia, V. A. (2014). Análise da interação terapêutica em intervenções com universitários com transtorno de ansiedade social (Dissertação de mestrado). Recuperado de Repositório Institucional UNESP.

Gonçalves, D. A., Mari, J. J., Bower, P., Gask, L, Dowrick, C., Tófoli, L. F., Campos, M., Portugal, F. B., Ballester, D., Fortes, S. (2014). Brazilian multicentre study of common mental disorders in primary care: rates and related social and demographic factors. Cadernos de Saúde Pública, 30(3), 623-632.

Herman H. M., Siu Man, Chan, C. L. W., Lam, K. F., \& Lau, B. H. P. (2013). The Chinese medicine construct "stagnation" in mind-body connection mediates the effects of mindfulness training on depression and anxiety. Complementary Therapies in Medicine, 21, 348-357. doi: http:// dx.doi.org/10.1016/j.ctim.2013.05.008

Johansson, R., Carlbring, P., Heedman, A., Paxling, B., \& Andersson, G. (2013). Depression, anxiety and their comorbidity in the Swedish general population: Point prevalence and the effect on health-related quality of life. PeerJ, 1, 1-18.

Kazdin, A. E. (1982). Single-case research designs. New York, NY: Oxford University Press.

Leonardi, J. L., \& Meyer, S. B. (2015). Prática Baseada em Evidências em Psicologia e a História da Busca pelas Provas Empíricas da Eficácia das Psicoterapias. Psicologia Ciência e Profissão, 35(4), 1139-1156.

Melo, E. M. O., Aureliano, L. G., \& Zamignani, D. R. (2014). Classificação dos comportamentos verbais vocais do terapeuta de casal a partir do SiMCCIT: uma aplicação possível? In D. R. Zamignani, \& S. B. Meyer (Orgs.) Pesquisa de Processo em Psicoterapia: Estudos a partir do Instrumento SiMCCIT (pp. 57-74) São Paulo: Paradigma Núcleo de Análise do Comportamento.

Meyer, S. B., Del Prette, G., Zamignani, D. R., Banaco, R. A., Neno, S., \& Tourinho, E. Z. (2010). Análise do comportamento e terapia analítico-comportamental. In E. Z. Tourinho \& S. V. Luna (Orgs.), Análise do comportamento: Investigações histórias, conceituais e aplicadas (pp. 153-174). São Paulo: Roca.

Newby, J. M., Mackenzie, A., Williams, A. D., Mcintyre, K., Watts, S., Wong, N., \& Andrews, G. (2013). Internet cognitive behavioural thera- 
py for mixed anxiety and depression: a randomized controlled trial and evidence of effectiveness in primary care. Psychological Medicine, 43, 2635-2648.

Organização Mundial da Saúde. (2017). Depression and Other Common Mental Disorders: Global Health Estimates. Genebra: Autor. Licença: CC BY- NC-SA 3.0 IGO.

Orti, N.P., Bolsoni-Silva, A. T., Grecco, M. K., \& Matsunaka, M. P. (2015). Parent intervention with mothers of children with internalizing problems: analysis of complaints, themes and therapist-client interaction in three clinical cases. Journal of Psychological Abnormalities, 4(2), 363 - 376.

Koerner, K. (2018). Science in practice. Em. S. C. Hayes, \& S. G Hofmann. (Orgs.), (2018). Process-based CBT: the science and core clinical competencies of cognitive behavioral therapy (pp. 45-66). Oakland, CA: New Harbinger.

Kroenke, K., Spitzer, R. L., \& Williams, J. B. W. (2001). The PHQ - 9 Validity of a Brief Depression Severity Measure. Journal of General Internal Medicine, 16(9), 606-613.

Oshiro, C. K. B., \& Meyer, S. B. (2014). Desafios metodológicos na pesquisa clínica: terapia com clientes difíceis. In D. R. Zamignani, \& S. B. Meyer (Orgs.) Pesquisa de Processo em Psicoterapia: Estudos a partir do Instrumento SiMCCIT (pp. 105-144) São Paulo: Paradigma Núcleo de Análise do Comportamento.

Ruiz-Sancho, E. M., Frojan-Parga, M. X., \& CaleroElvira, A. (2013). Functional Analysis of the Verbal Interaction Between Psychologist and Client During the Therapeutic Process. Behavior Modification, 37(4), 516-542.

Shaughnessy, J. J., Zechmeister, E. B., \& Zechmeister, J. S. (2012). Metodologia de Pesquisa em Psicologia (9a ed.). McGraw Hill Brasil.

Shinohara, H. (2000). Relação Terapêutica: O que sabemos sobre ela? In R. R. Kerbauy (Org.), Sobre comportamento e cognição. (pp. 218-224) Santo André: Esetec.

Starr, L. R., Hammen, C., Connolly, N. P., \& Brennan, P. A. (2014). Does relational dysfunction mediate the association between anxiety disorders and later depression? Testing an interpersonal model of comorbidity. Depression and Anxiety, 31, 77-86. doi: 10.1002/da.22172
Silveira, J. M., \& Kerbauy, R. R. (2000). A interação terapeuta-cliente: uma investigação com base na queixa clínica. In: R. R. Kerbauy, Sobre comportamento e cognição (pp. 213-221) Santo André: Esetec.

Sturmey, P. (2009). Behavioral Activation Is an Evidence-Based Treatment for Depression. Behavior Modification, 33(6), 818-829.

Skinner, B. F. (2003). Ciência e Comportamento Humano. 11a ed. São Paulo: Martins Fontes.

Van Beek, M. H. C. T., Oude Voshaar, R. C., Beek, A. M., Van Zijderveld, G. A., Visser, S., Speckens, A. E. M., Batelaan, N., \& Van Balkom, A. J. L. M. (2013). A brief cognitive-behavioral intervention for treating depression and panic disorder in patients with noncardiac chest pain: a 24 -week randomized controlled trial. Depression and Anxiety, 30, 670-678. doi: 10.1002/da.22106

Zamignani, D. R., \& Andery, M. A. P. A. (2005). Interação entre terapeutas comportamentais e clientes diagnosticados com transtorno obsessivo- compulsivo. Psicologia: Teoria e Pesquisa, 21(1), 109-119.

Zamignani, D. R., \& Banaco, R. A. (2005). Um panorama analítico- comportamental sobre os transtornos de ansiedade. Revista Brasileira de Psicologia Comportamental e Cognitiva, 7(1), 77-92.

Zamignani, D. R. (2007). O desenvolvimento de um sistema multidimensional para a categorização de comportamentos na interação terapêutica (Tese de Doutorado) Recuperado de: Biblioteca Digital USP.

Zamignani, D. R., \& Meyer, S. B. (2007). Comportamento Verbal no contexto clínico: contribuições metodológicas a partir da análise do comportamento. Revista Brasileira de Terapia Comportamental e Cognitiva, 9(2), 241-259.

\section{Informações do Artigo}

\section{Histórico do artigo:}

Submetido em: 03/10/2018

Primeira decisão editorial: 11/06/2019

Aceito em: 25/06/2019 